\title{
Age differences in foraging and executive functions: A cross-sectional study
}

Authors: Inga María Ólafsdóttir†; Steinunn Gestsdóttir; \& Árni Kristjánsson.

Department of Psychology, School of Health Sciences, University of Iceland.

Corresponding author: Inga María Ólafsdóttir, Department of Psychology, School of Health Sciences, University of Iceland, 101 Reykjavík, Iceland. E-mail: $\underline{\text { imo4@hi.is }}$

\section{Acknowledgements}

This work was supported by the Research Fund of the University of Iceland, grant numbers, 1032397 and 1470-147-2701. We thank Dr. Andrey Chetverikov, Dr. Ian M. Thornton, and Dr. Tómas Kristjánsson for the development of the foraging task used in the current study. 


\begin{abstract}
Visual foraging tasks require participants to search for multiple targets among numerous distractors. Foraging paradigms enable insights into the function of visual attention above what has been learned from traditional single target search paradigms. These include attentional orienting over time and search strategies involving target selection from different target types. To date, only a handful of studies have been conducted on the development of foraging abilities. Here, the foraging of five age groups, children aged six, nine, twelve, and fifteen, and adults, was measured, as well as their performance on various tasks assessing four subdomains of executive functions; inhibition, attentional flexibility, working memory, and problem solving. Executive functions consist of a complex network of independent but interconnected cognitive processes that regulate action orienting and goal directed behavior, and have been shown to be connected to visual attention and attentional orienting. Our results show that foraging abilities improve dramatically from ages six to twelve, when adult levels of foraging have been reached. This is evident from reduced foraging times, increasingly frequent switches between target types, lower switch costs, and reduced error rates. In addition, PLS-SEM modelling reveals that the age differences on the foraging tasks are predominantly indirect effects through executive functions. In other words, the development of successful foraging abilities is dependent upon the maturation of executive functions.
\end{abstract}


Imagine that you're sitting with a child, playing with LEGOs. The child decides that she wants to build a white house with a red roof and starts sifting through the LEGOs, separating the red and white ones from blocks of other colors. This is an example of foraging, defined as continuous search for multiple target items among multiple distractors (Kristjánsson, Jóhannesson, \& Thornton, 2014; Ólafsdóttir, Gestsdóttir, \& Kristjánsson, 2019; Ólafsdóttir, Kristjánsson, Gestsdóttir, Jóhannesson, \& Kristjánsson, 2016; Wolfe, 2013; see review in Kristjánsson, Ólafsdóttir \& Kristjánsson, 2019). The task requires many cognitive operations, such as recognizing the relevant blocks and guiding gaze and hands towards them while avoiding other blocks, operations that are typically thought to involve executive functions and attention.

While there is a long tradition of assessing visual attention with single-target visual search tasks (Bravo \& Nakayama, 1992; Treisman \& Gelade, 1980; Wolfe, 1994; see recent reviews in Kristjánsson, 2015; Kristjánsson \& Egeth, 2020; Wolfe \& Horowitz, 2017), recent studies of multi-target visual foraging have allowed the study of attentional orienting over time with a more dynamic task than when only a single target is to be found. This line of research originates from studies on animals that forage for food in the wild (see e.g. Bukovinszky, Rikken, \& Evers, 2017; Dawkins, 1971; Mallott, Garber, \& Malhi, 2017; Pyke, Pulliam, \& Charnov, 1977) but computerized foraging tasks where humans are tested have more recently been introduced (Kristjánsson et al., 2014; Wolfe, 2013). Studying visual attention by using foraging tasks enables investigations of how attention is allocated over time and how people attend to multiple targets that differ by type. This allows for inquiries into, for example, how and when people switch between target types and the cost of switching, in addition to more traditional measures of visual attention, such as RTs and the differences between performance on tasks with high and low attentional load. 


\section{Attentional Load and Foraging}

It has been well established that manipulating the attentional load of a task alters a subject's performance. For instance, when observers search for a target that is distinguished from distractors by a single feature, it tends to pop out, and the search is fast and effortless regardless of the number of distractors in the display (Maljkovic \& Nakayama, 1994; Treisman \& Gelade, 1980). However, when targets are defined by a conjunction of features, and attentional load is therefore higher, search times increase as a function of the number of distractors (Treisman \& Gelade, 1980; Wolfe, 1994; see Kristjánsson \& Egeth, 2020, for a recent review).

Continuing with our LEGO analogy, foraging for white and red LEGOs would be an example of a feature foraging task, where the blocks are distinguished from distractors by a single feature, in this case, color. But when the house in our example is almost ready, we may need only square blocks. Now the task has turned into a conjunction foraging task, where the targets are defined by both color and shape.

Foraging studies using this feature-conjunction manipulation have shown that throughout foraging trials where observers must find all targets of a particular type, intertarget times (ITTs; the time between each tap on a target) of feature and conjunction trials are typically very similar. The largest differences in completion times between these paradigms stem from distinct peaks or rises in ITTs of conjunction foraging trials that appear when observers switch between target types and at the end of each trial (Kristjánsson, Thornton, \& Kristjánsson, 2018; Kristjánsson, Thornton, Chetverikov \& Kristjánsson, 2020; Ólafsdóttir et al., 2019). End peaks also appear for feature foraging but tend to be much smaller than during conjunction foraging. Interestingly, end peaks during conjunction, but not feature foraging, become larger as distractor number rises, corresponding well with how RTs rise in accordance with the number of distractors in single target conjunction search (Kristjánsson et al., 2020). 
Another useful measure in foraging tasks involves the number of runs per trial, which provides important information about foraging strategies. A run is defined as the consecutive selection of the same target type. The more frequently an observer switches between target types during a trial, the more runs the trial will be completed in. Kristjánsson et al. (2014) found that the number of runs per trial is affected by attentional load. When targets are defined by a single feature and attentional load is low, switching between target types typically occurs at random, but when targets are defined by a conjunction of features and attentional load is higher, subjects tend to repeatedly select the same target type, therefore completing most foraging trials in two runs.

The insights from these foraging paradigms demonstrate the added information gained from studying visual attention over time with dynamic tasks and the importance of investigating constructs from varied perspectives.

\section{Development of Visual Attention}

As with the literature on adult observers, the development of visual attention in childhood has mainly been investigated with single-target search tasks. A common finding is that young children have difficulty finding targets defined by a conjunction of features (Donnelly et al., 2007; Merrill \& Conners, 2013; Merrill \& Lookadoo, 2004; Taylor, Chevalier, \& Lobaugh, 2003; Trick \& Enns, 1998; Woods et al., 2013). In those tasks, even when there are only two items on the screen, one target and one distractor, search times of children younger than 10 years tend to be approximately double the search times of young adults (see e.g. Hommel, Li, \& Li, 2004; Trick \& Enns, 1998). Plots displaying RTs against set size provide information about how adding distractors to displays affect search. In conjunction search, plotting the RT against the number of distractors tends to result in steep slopes, but in feature search tasks they are flat, meaning that no matter how many distractors appear, the target 'pops out' and RTs do not increase. Children's search slopes during 
conjunction search tasks tend to be much steeper than those of young adults, emphasizing the difficulties they have with the task (Merrill \& Conners, 2013; Merrill \& Lookadoo, 2004; Trick \& Enns, 1998). Performance on feature-based search tasks, on the other hand, is similar to that of adults; children's search slopes are relatively flat (Donnelly et al., 2007; Merrill \& Conners, 2013), even for toddlers (Gerhardstein \& Rovee-Collier, 2002) and infants as young as two months (Adler \& Orprecio, 2006). These results suggest that feature and conjunction based search tasks rely on different mechanisms, and that abilities for feature search are innate or develop in the first few months of life, while mechanisms necessary for conjunction search mature slowly and continue to develop throughout childhood (see e.g. Gerhardstein \& RoveeCollier, 2002; Taylor et al., 2003).

However, Ólafsdóttir et al. $(2016 ; 2019)$ found that, in contrast to single-target visual search studies (Gerhardstein \& Rovee-Collier, 2002; Donnelly et al., 2007; Merrill \& Conners, 2013; Merrill \& Lookadoo, 2004), young children have more difficulty than adults finding targets that are defined by only a single feature. Adult observers tend to switch randomly between target types during feature foraging and switch costs are small (Kristjánsson et al., 2014; Ólafsdóttir et al., 2019), while young children tend to forage in long runs and switches between target types result in considerably slowed foraging (Ólafsdóttir et al., 2016; 2019, see also Gil-Gómez de Liaño, Quirós-Godoy, Pérez-Hernández, Cain, \& Wolfe, 2018).

\section{Executive Functions}

Previous research has established that the development of visual attention is at least partly dependent upon executive functions (Jenkins \& Berthier, 2014; Longstaffe, Hood, \& Gilchrist, 2014; Trick \& Enns, 1998; Woods et al., 2013). Executive functions consist of distinct but interconnected cognitive mechanisms that control action orienting and goal directed behaviors (Anderson, 2002; Best, Miller, \& Jones, 2009; Miyake et al., 2000). While 
early research focused on whether executive functions could be considered a unitary construct or consist of separate components, recent disputes have focused on which cognitive processes comprise the executive functioning network and how they relate to one another (Best et al., 2009; Best \& Miller, 2010; Brocki \& Bohlin, 2004; Wu, Chan, Leung, Leung, \& Ng, 2011). In recent years, a general consensus seems to have emerged that working memory, inhibition, and attentional flexibility are core functions in this network (Best et al., 2009; Best \& Miller, 2010; Miyake et al., 2000; Zelazo, 2015; Zelazo, Blair, \& Willoughby, 2016).

Working memory refers to the ability to update, maintain and manipulate information in memory, inhibition is the capability to refrain from prepotent responses when required, and attentional flexibility, or shifting, is the ability to switch between mental sets or tasks, disengaging from one aspect of a task, and engaging with another one (Lee, Bull, \& Ho, 2013; Wu et al., 2011). These different aspects or subcomponents of executive functions mature at different rates (Diamond, 2002; Isquith, Gioia, \& Espy, 2004; Wu et al., 2011, for reviews, see Best et al., 2009; Best \& Miller, 2010), which supports the argument that executive functions are not a unitary construct, but a network of distinct but interconnected components (Best et al., 2009). Inhibition develops rapidly at an early age, but improvement slows down considerably after the preschool years (Davidson, Amso, Anderson, \& Diamond, 2006; Klenberg, Korkman, \& Lahti-Nuuttila, 2001; Pureza, Gonçalves, Branco, Grassi-Oliveira, \& Fonseca, 2013). In relatively simple inhibition tasks, adult levels of performance are frequently reported to have been reached at around age 12 (Brocki \& Bohlin, 2004; Huizinga, Dolan, \& van der Molen, 2006; Wu et al., 2011), but some studies have found ceiling effects of performance even earlier, such as at six (Klenberg et al., 2001) or seven years (Johnstone et al., 2007). In more complex tasks, continued improvements can be seen into adolescence (Huizinga et al., 2006) and even early adulthood (Huizinga et al., 2006; Leon-Carrion, GarciaOrza, \& Perez-Santamaria, 2004). Working memory develops later than inhibition and shows 
linear improvement into adolescence (Gathercole, Pickering, Ambridge, \& Wearing, 2004; Lee et al., 2013). Attentional flexibility appears to be dependent on inhibition and working memory, since task switching includes remembering a set of rules and suppressing a previous mental set and/or response in order to produce the new one (Davidson et al., 2006; Diamond, 2002; Miyake et al., 2000). Like working memory, attentional flexibility continues to improve throughout adolescence (Anderson, 2002; Davidson et al., 2006; Huizinga et al., 2006).

Tasks that measure complex executive functions, such as planning and problem solving, also seem to tax the core executive functions described above (Best et al., 2009). In these tasks, observers must find a strategy for completing the task, remember this strategy, evaluate progress, switch tactics if needed, and even inhibit responses to evaluate their merit. Planning and organization seem to mature at a later age than the core executive functions (Huizinga et al., 2006; Pureza et al., 2013). These skills develop rapidly between the ages 7 and 10, but a regression in performance has been reported between ages 11 and 13, where the children prefer cautious and conservative approaches (Anderson, 2002). Continued improvements in problem solving abilities are then observed into adulthood (Huizinga et al., 2006; Pureza et al., 2013).

Notably, all these executive function abilities are important for efficient visual foraging. Findings from the visual search literature show that observers tend to attend preferentially to the same type of targets as have been attended before (Brascamp, Blake, \& Kristjánsson, 2011; Chetverikov \& Kristjánsson, 2015; see Ásgeirsson \& Kristjánsson, 2019, for review). Inhibiting "primed" responses could facilitate switching between target types. Additionally, inhibition should lower erroneous taps on distractors. Working memory is considered necessary for maintaining templates of targets (Awh \& Jonides, 2001; Bundesen, 1990). Attentional flexibility should facilitate switching between target types (Huizinga et al., 2006), resulting in more runs and lower switch costs. Problem solving abilities should help 
observers formulate and evaluate strategies for trial completion (Pureza et al., 2013), resulting in fewer errors and faster foraging. Although these functions can be measured independently, it is important to note that they are interconnected. Indeed, even though studies on adults have supported Miyake et al.'s (2000) three factor model of executive functions, some studies on children have found that a one factor model fits the data best when preschool aged children are tested (Wiebe et al., 2011; Willoughby, Blair, Wirth, \& Greenberg, 2010; Willoughby, Wirth, \& Blair, 2012), and a two-factor structure is more reflective of executive functions up to age 15 (Lee et al., 2013). All in all, regardless of whether the subcomponents of executive functions are measured separately or in combination, greater executive functioning abilities should contribute to successful foraging.

\section{The Current Study}

While our previous studies (Ólafsdóttir et al., 2016; 2019) have provided important information about the relation between foraging performance and executive functions both among young children aged four to seven years, as well as among children aged 11 to 12 years, for a clearer a picture, a direct comparison for a number of different age groups is needed. In the current study, we assess the foraging performance and executive functions of five different age groups ranging from six years to adulthood. To our knowledge, this is the first comprehensive cross-sectional study of cognitive development and visual foraging. Our aim is to provide answers to important questions about whether executive functions affect attentional orienting. Previous studies have mainly used single-target visual search tasks but using the foraging task allows for more diverse performance assessment, because of the many dependent measures involved in the paradigm.

Regarding foraging performance, we expected to replicate previous results (Ólafsdóttir et al., 2016; 2019) and see improvements on all aspects of the foraging task up until age 12, when children should have reached adult levels of performance. In line with previous research 
(Kristjánsson et al., 2014; Kristjánsson et al., 2018; Ólafsdóttir et al., 2016; 2019) we expected feature foraging trials to be completed with greater ease than conjunction foraging trials, resulting in more runs per trials, faster foraging, and lower switch costs and error rates. We expected to see these differences between the two foraging conditions across all age groups.

Lastly, we explored the connection between foraging performance, age, and executive functions, with partial least squares structural equation modeling (PLS-SEM). Some previous studies have not shown any connection between executive functions and foraging (Jóhannesson, Kristjánsson, \& Thornton, 2017), while others have shown that attentional flexibility (Ólafsdóttir et al., 2019) and/or working memory (Ólafsdóttir et al., 2016; 2019, Quirós-Godoy, Pérez-Hernández, Cain, Wolfe, \& Gil-Gómez de Liaño, 2018) affect foraging performance. We expected to find that age affects both executive functions and foraging and that executive functions affect foraging above and beyond the effects of age.

\section{Method}

\section{Participants}

A total of 86 participants from five age groups partook in the study. Children aged six, nine, twelve, and fifteen years, and adults (see Table 1). The children came from two schools in the same school district of Reykjavík. All the children in each age group were in the same school year. The adult group consisted of 23 undergraduate students. Data from three adult participants was removed due to color blindness. All remaining participants had normal or corrected to normal eyesight.

Information about the study and consent forms were sent home with all the children for their parents to sign. Children aged 12 and 15 were asked to give their assent by signing the forms along with their parents, but verbal assent was obtained from the 6 and 9-year-old children. 
Table 1. Participant characteristics.

\begin{tabular}{llllll}
\hline & $\begin{array}{l}\text { Number of } \\
\text { participants }\end{array}$ & Age span & $\begin{array}{l}\text { Mean age } \\
\text { (years) }\end{array}$ & Sd (years) & Gender \\
\hline 6 years old & 18 & $5.84-6.69$ & 6.24 & 0.30 & 10 girls/8 boys \\
9 years old & 16 & $9.06-9.78$ & 9.44 & 0.22 & 11 girls 5 boys \\
12 years old & 16 & $11.92-12.78$ & 12.29 & 0.27 & 11 girls $/ 5$ boys \\
15 years old & 16 & $14.93-15.81$ & 15.42 & 0.28 & 12 girls $/ 4$ boys \\
Adult & 20 & $21.88-48.63$ & 25.55 & 6.03 & 12 female $/ 8$ male \\
\hline
\end{tabular}

The adult participants were students in an undergraduate class in psychology and were offered class credit for their participation in the study. The children did not receive any compensation for their participation. All aspects of the experiment were reviewed and approved by the Icelandic National Bioethics Committee, the data protection authority, and permission was granted by the Reykjavik Department of Education and Youth, as well as school administrations from both schools.

\section{Experimental Settings}

The experiment was run in a quiet room with normal illumination. The adult participants were tested in the lab while the children were tested two at a time at their school, with one participant starting with Tower of London and foraging task, and the other participant with the EF tasks. The six-year-old participants finished two 25-minute sessions on different days, with a maximum of one week between them. They completed the foraging and the Tower of London tasks in one session and the three EF tasks in the other. The older children and adults completed all tasks in one 40-50-minute session. The order of all tasks was counterbalanced, as well as foraging condition, and the color and shape of targets and distractors, during foraging. Each task started with a few practice trials.

\section{The Foraging Task}

Equipment. The foraging task was presented on an iPad 2 with screen dimensions of $20 \times 15 \mathrm{~cm}$ and an effective resolution of $1024 \times 768$ pixels, placed on a table in front of participants in landscape mode, so that viewing distance was approximately $50 \mathrm{~cm}$. Stimulus 
presentation and response collection were carried out with a custom iPad application written in Swift using Xcode.

Stimuli and measures. Each trial started with 40 stimuli on a black background, half of which were targets and half distractors. On feature foraging trials, the stimuli were red, green, yellow, and blue disks. On conjunction foraging trials, the stimuli were red and green discs and squares. Their diameter was 20 pixels (approximately $0.46^{\circ}$ visual angle). The items were distributed randomly on a non-visible 10 x 8 grid and offset from the screen edge by 100 x 150 pixels. The viewing area therefore occupied 12 x $15 \mathrm{~cm}$ (approximately $13.7 \times 17.1^{\circ}$ ). The position of each item within the grid was randomized by adding a random vertical and horizontal offset. Gaps between columns and rows ensured that items never occluded or approached one another. The location of the targets and distractors was randomly generated from trial to trial (see Figure 1).
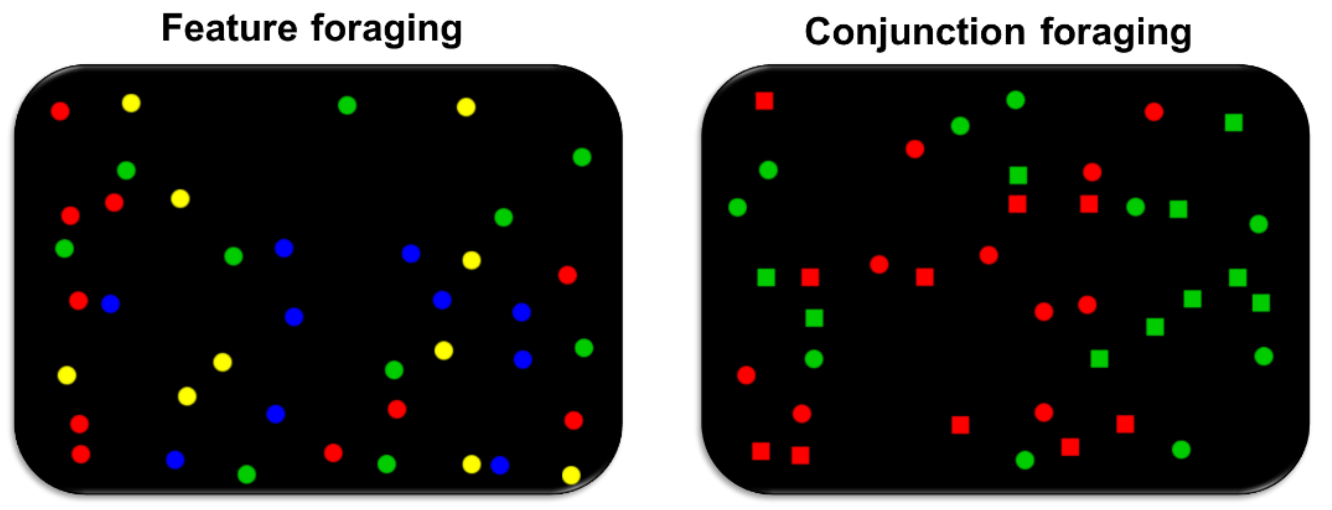

Figure 1. Screenshots of the foraging task. The left panel shows a feature foraging trial and the right panel shows a conjunction foraging trial.

Procedure. Participants were asked to complete ten trials of each of the two foraging conditions. They were informed that the first trial of each condition would be for practice, but the remaining nine trials constituted the task itself. Participants were instructed to tap all of the targets as quickly as possible with the index finger of their dominant hand but avoid the 
distractors. In feature foraging trials, the red and green discs were the targets and the yellow and blue discs distractors for half of the participants; reversed for the other half. During conjunction foraging, the red discs and green squares were the targets and the green discs and red squares distractors for half of the participants, and vice versa for the other half. Each trial was started by tapping anywhere on the screen. The targets disappeared upon being tapped. If a distractor was tapped, an error message appeared, and the trial was restarted. The participants were asked to complete each trial as quickly as possible without making errors, and informed that they could take a break between any two trials.

\section{Executive Functions}

Equipment. The computerized EF tasks were administered on a 17.3" laptop computer screen with an effective resolution of $1600 \times 900$ pixels. Task presentation and response collection were carried out with the Amsterdam Neuropsychological Tasks (ANT) program (De Sonneville, 1999).

The Tower of London DX $2^{\text {nd }}$ edition (Culbertson \& Zillmer, 2005) consists of two wooden tower-structure boards and two sets of plastic beads, scoring sheets, and a stopwatch.

Stimuli and measures. The ANT program is a test battery containing 38 tasks developed to assess neuropsychological functions of children and adults aged 3-80 years. The test battery enables the evaluation of various aspects of attention, information processing, and executive functions (De Sonneville, 1999).

Procedure. Three tasks from the ANT tasks program were administered to measure inhibition, attentional flexibility, and working memory. The Tower of London task was administered to measure problem solving.

Go/no-go. In the task a grey square with wide yellow borders appears on a black background. The border can either surround the square or there can be a gap in the middle of its bottom line (see Figure 2). The Go/no-go task measures simple inhibition. The only 
requirement for that task is inhibition of prepotent responses, without confounding from other functions, such as working memory (Best et al., 2009).

Participants were asked to look at the squares carefully and informed that a square would appear in the middle of a black screen. If it had a notch in it (75\% of trials), participants were asked to press a button on the keyboard as quickly as possible but do nothing if it did not ( $25 \%$ of trials). The response key was always on the same side of the keyboard as the participant's dominant hand. The squares appeared in a pseudorandom order and each presentation lasted for $800 \mathrm{~ms}$, or until a response was made. Participants performed 48 trials.

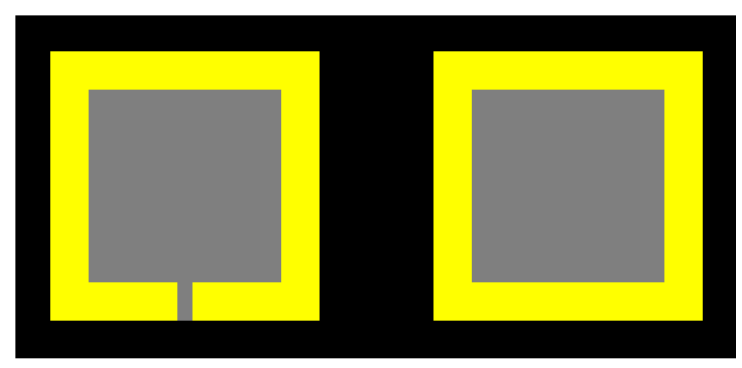

Figure 2. The two squares that were presented in the Go/no-go task. The left panel shows the square that represented "go" trials. The right panel shows the square representing "no-go" trials. Figure from the Amsterdam Neuropsychological Tasks manual (De Sonneville, 2011).

Attentional flexibility. In the task, a disc appears to the left or right of a white fixation cross on a black background. In the first part, the disc is always green, and participants were to press the response key on the same side as the disc appeared. In the second part the disc is always red the participant was asked to press the response key on the opposite side, and in the third part, the disc can be either red or green. The first part assesses baseline response speed, the second part assesses inhibition of prepotent responses and the production of alternate ones, which can be classified as a complex inhibition task (see e.g. Best et al., 2009), The third part assesses set shifting, the participant needs to hold two rules in mind and switch between them according to which stimulus appears on the screen. 
The discs remained on the screen until participants pressed a response button, but for a maximum of $7000 \mathrm{~ms}$ if no response was made. Responses were valid if they occurred between 200 and $6000 \mathrm{~ms}$ after stimulus appearance. The ITI was $1200 \mathrm{~ms}$. If a participant missed a trial, a trial was added at the end of the session to ensure that response numbers were the same for every participant. Before each part, participants were given instructions about the stimuli and how to respond. Parts one and two consisted of thirty trials each and part three of sixty trials, so that each color appeared thirty times (the side they appeared on, and their color in part three in pseudorandom order).

Working memory. . The memory search task assesses the maintenance and uploading of working memory content. Participants were asked to memorize a geometrical colored shape (e.g. a blue square). Four geometrical shapes appeared on a black screen, and participants were instructed to press a key if the memorized shape was among the four shapes, and a different key if not. In the second part, participants were asked to memorize three different colored shapes. If at least one of the memorized shapes appeared on the screen, participants were instructed to press a particular key and a different key if none of the shapes appeared. The key indicating the yes-response was always on the same side as the participant's dominant hand. The shapes appeared in pseudorandom order, with a target present on half of the trials. They remained on screen until a response was made, but for a maximum of $7000 \mathrm{~ms}$. A mask appeared for $1200 \mathrm{~ms}$ before the next trial started. Responses were valid if they occurred between 200 and 6000 ms after the stimuli appeared. Each part of the task started with 12 practice trials, after which participants were asked if they still remembered the shape/s and were allowed to look at them again before the task started. Each part of the session was 48 trials, but if no response was made, the same shapes appeared again at a different location, holding the number of responses constant across participants. 
Problem solving. Lastly, The Tower of London DX $2^{\text {nd }}$ edition measures higher order problem solving ability. The participant is required to develop an action plan, identify sub goals, organize them, and self-monitor their progress, while maintaining the solution in working memory (Culbertson \& Zillmer, 2005).

The researcher and participant sat opposite each other, each with a wooden board with three pegs of different sizes in front of them. The researcher explained that they would arrange the beads on the pegs in different patterns and the participant should make the same patterns on their own board, by using as few moves as possible. There were two practice trials before ten experimental trials. The trials became more complicated as the task progressed. The researcher counted the number of moves and timed participants. If the participant took longer than two minutes to complete a trial, the researcher invited them to try the next one.

\section{Data Analysis}

Foraging. The measures of the foraging task involve 1) Inter-target times (ITTs) which are defined as the time that passes between each tap on a target. 2) Number of runs, where a run is defined as the consecutive selection of the same target type (with two target types, 10 of each, the minimum run number is two, if all targets of one type are tapped before the observer switches to the next target type. The maximum run number is 20 , when observers always switch between target types). 3) Switch costs, which are calculated by finding the mean ITTs of the first tap in each run, where participants switch from the other target type and the mean ITTs of the consecutive taps within the run and subtracting the latter from the former. 4) Error rates, involving how often observers tapped a distractor.

The first trial of each foraging condition (feature and conjunction) was regarded as a practice trial and removed from the data set. A series of mixed-measures ANOVAs with Tukey HSD post-hoc comparisons were run to assess both age differences in foraging and differences between foraging conditions. 
Executive functions. To measure attentional flexibility, the response times of correct trials in the first part of the attentional flexibility task, which measures baseline speed, were subtracted from response times of correct trials in the third part, where the task demands changed constantly (see e.g. Brunnekreef et. al., 2007; Mesotten et. al., 2012; Schuitema et. al., 2013, for previous research using the same method). By subtracting baseline speed from the RTs of the third part of the task, individual differences in response speed are controlled for, and a purer measure of how switching between task objectives slows responses down is obtained. The number of false alarms was used to assess performance in the Go/no-go task. Preliminary analyses of data from the working memory task showed error rates of around $20 \%$, with no intergroup differences. Response times of hits (correct, target present, trials) were therefore used to measure age differences. The number of moves in in the Tower of London task was used as a measure of problem-solving ability.

Due to collinearity of the executive functioning measures and a relatively small sample, reflective PLS-SEM modeling was used to explore the relationship between executive functions and foraging. PLS-SEM is a dimension reduction method that combines principal component analysis (PCA) and regression-based path analysis to estimate partial model structures (Hair, Risher, Sarstedt, and Ringle, 2019; Ringle, Sarstedt, Mitchell, \& Gudergan, 2018). As in PCA, PLS-SEM combines indicator variables linearly to use as proxies for components, or latent variables, that are believed to explain the variance of target constructs in the model (Ali, Rasoolimanesh, Sarstedt, Ringle, \& Ryu, 2018). The difference is that with the PLS-SEM method, instead of maximizing the explained variance of the independent variables the latent variables are created by minimizing the error variance of the dependent variables (Geladi \& Kowalski, 1986). This method is often viewed as an alternative to covariance-based SEM (CB-SEM; Jöreskog, 1973), which considers only the common variance of the data in estimating model parameters. PLS-SEM, on the other hand, accounts 
for the total variance and uses it to estimate parameters (Hair et al., 2019). PLS-SEM avoids numerous restrictions of CB-SEM, such as sample size requirements and assumptions about residual distribution and observational independence (Chin, 1998; Ringle et al., 2018). The PLS-SEM method can therefore be used with small sample sizes and is an appealing option when dealing with collinearity as in the current data set (Henseler, Ringle, \& Sinkovics, 2009).

Bias-corrected and accelerated (Bca) bootstrapping with 10,000 subsamples was used to carry out significance testing. To evaluate the model's predictive powers, both blindfolding and PLSpredict were carried out. Blindfolding is a method for obtaining cross validated redundancy and communality of both latent variables and indicators. The omission distance was set at 7 which means that the algorithm omits every 7 th data point of the indicators and does 7 iterations. Estimates from these iterations are combined to compute the Stone-Geisser $\mathrm{Q}^{2}$, which is the cross-validated redundancy of a reflectively modeled latent variable. Smaller differences in original and predicted values result in higher $\mathrm{Q}^{2}$ values, indicating greater predictive power (Geisser, 1974; Ringle et al., 2018; Sarstedt, Ringle, Smith, Reams, \& Hair, 2014; Stone, 1974).

PLSpredict uses k-fold cross-validation, where the data set is split into k equally sized subgroups, combines 1-k subgroups into a training sample which then predicts the remaining subgroup. The cross-validation is then repeated $\mathrm{k}$ times so that each subgroup will be left out of the training sample once (Shmueli et al, 2019). It is important to ensure that the training sample size meets the minimum sample size requirements for the model. In the current study, the $\mathrm{k}$ value was set to 10 , which is the convention if sample size allows for it (Shmueli et al., 2019). 


\section{Results}

\section{Age Differences in Foraging}

Figure 3 shows four measures of foraging performance by age and foraging condition. Foraging improved with age in all measures. Older participants forage more quickly, $\mathrm{F}(4,81)$ $=67.092, p<0.001, \eta_{p}{ }^{2}=0.768$, and their switch costs and error rates are lower, $\mathrm{F}(4,81)=$ 12.101, $p<0.001, \eta_{p}{ }^{2}=0.374$, and $\mathrm{F}(4,81)=9.782, p<0.001, \eta_{p}{ }^{2}=0.326$, respectively. Older participants are also more prone to switching between target types within trials, resulting in higher run numbers, $\mathrm{F}(4,81)=6.660, p<0.001, \eta_{p}{ }^{2}=0.247$. Figure 3 also reveals large differences between foraging conditions; there was a significant difference in the number of runs by foraging condition, $\mathrm{F}(1,81)=132.651, p<0.001, \eta_{p}{ }^{2}=0.621$, but no interaction with age $(p=0.105)$. There was also a difference in foraging speed by condition, $\mathrm{F}(1,81)=214.703, p<0.001, \eta_{p}{ }^{2}=0.726$, with subjects of all ages foraging more quickly during feature foraging (see Figure 3). The interaction between condition and groups was also significant, $\mathrm{F}(4,81)=8.296, p<0.001, \eta_{p}{ }^{2}=0.291$. The difference in switch costs between foraging conditions was also significant, $\mathrm{F}(1,81)=98.076, p<0.001, \eta_{p}{ }^{2}=0.548$, as well as the interaction between age and foraging condition, $\mathrm{F}(4,81)=3,178, p=0.018, \eta_{p}{ }^{2}=0.136$. Lastly, there was a significant difference in error rates between foraging conditions, $\mathrm{F}(1,81)$ $=50.505, p<0.001, \eta_{p}{ }^{2}=0.384$, with an interaction between age and foraging condition, $\mathrm{F}(4$, 81) $=7.383, p<0.001, \eta_{p}^{2}=0.267$.

A Tukey HSD post hoc comparison of the age differences shows that they are mainly due to six and nine-year-old children performing differently from the older age groups (see Table 2). Six-year-old children are the slowest foragers in both foraging conditions, followed by the nine-year-olds, but there was no significant difference between the foraging speed of the other age groups (all $p$ s $>0.939$ ). Six and nine-year-old children also made more errors than the other groups during conjunction foraging. 
a

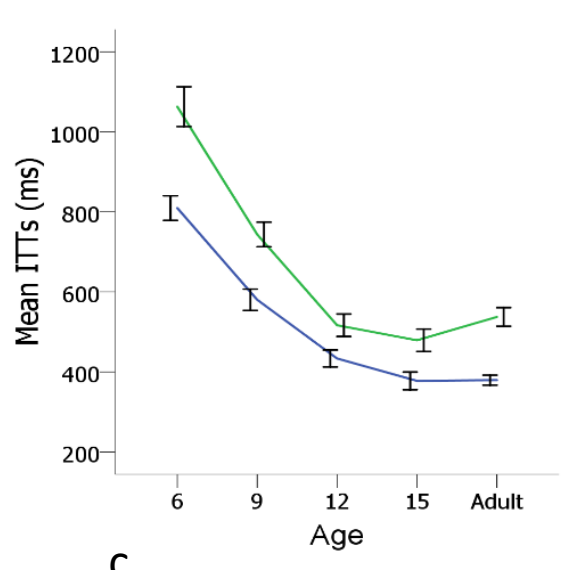

C

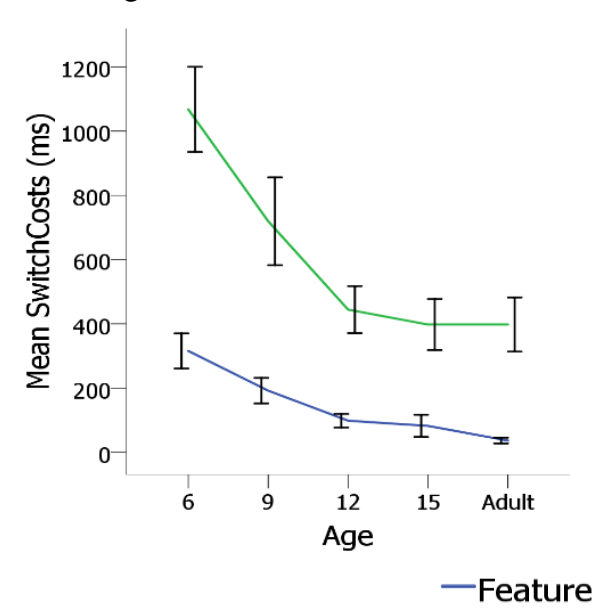

b
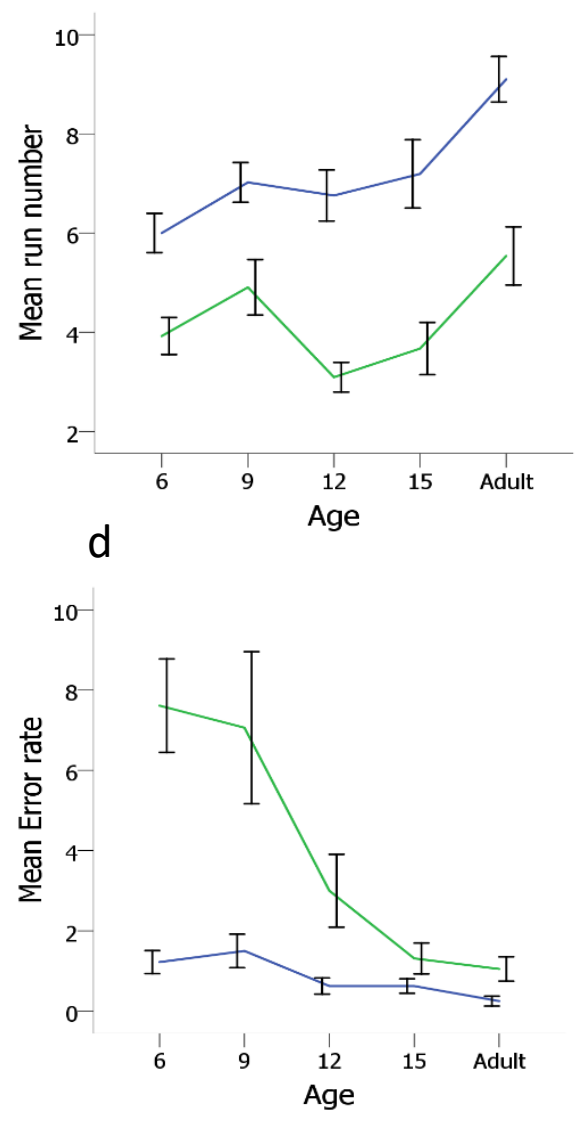

-Conjunction

Figure 3. Differences in foraging by age and condition. Panel A shows mean inter-target times per age group. Panel B shows the mean number of runs on a trial per age group. Panel C shows mean switch cost per age group, and panel D shows mean error rates in a trial per age group. Blue lines represent feature foraging and green lines conjunction foraging. Error bars show +/- 1 SEM.

The switch costs of six-year-olds were also significantly higher than the switch costs for the older observers during conjunction foraging, with the difference between six and nine-yearolds close to significance $(p=0.057)$. When looking at these three measures, it seems that foraging performance continues to improve up until late childhood, where it starts to level off. The only measure that continues to show improvement up until adulthood is the number of runs. During feature foraging, adult participants foraged in significantly more runs per trial than both six and 12-year-old observers. 
Table 2. Mean performance of each age group in all foraging measures.

\begin{tabular}{|c|c|c|c|c|}
\hline \multicolumn{5}{|c|}{ Feature foraging } \\
\hline & ITTs (ms) & Switch costs (ms) & Runs (n) & Errors (n) \\
\hline 6 years & $809.47_{2 * * 3 * * 4 * 5 * *}$ & 315.54 & $6.00_{5^{* *}}$ & 1.22 \\
\hline 9 years & $580.261 * * 3 * 4 * * 5 * *$ & 191.87 & 7.02 & 1.50 \\
\hline 12 years & $433.54_{1 * * 2 *}$ & 98.34 & $6.76_{5} *$ & 0.63 \\
\hline 15 years & $377.69_{1 * 2 * *}$ & 82.15 & 7.19 & 0.63 \\
\hline Adults & $379.54_{1} * 2 * *$ & 36.47 & $9.1_{1 * * 3 *}$ & 0.25 \\
\hline \multicolumn{5}{|c|}{ Conjunction foraging } \\
\hline 6 years & $1062.722 * * 3 * * 4 * * 5 * *$ & $1067.66_{3} * * 4 * 5 * *$ & 3.92 & $7.61_{3 * * 4 * * 5 * *}$ \\
\hline 9 years & $743.48_{1} * * 3 * * 4 * 5^{* *}$ & 719.30 & 4.91 & $7.063^{* * *} 4^{* * 5 * *}$ \\
\hline 12 years & $516.66_{1 * * 2 * *}$ & $444.21_{1 * *}$ & $3.095 *$ & $3.00_{1 * * 2 * *}$ \\
\hline 15 years & $479.05_{1 * * 2 * *}$ & $397.73_{1 * *}$ & 3.67 & $1.31_{1 * * 2 * *}$ \\
\hline Adults & $537.44_{1 * * 2 * *}$ & $397.87_{1 * *}$ & $5.543^{*}$ & $1.05_{1 * * 2 * *}$ \\
\hline
\end{tabular}

Note: Subscripts indicate significant differences between groups according to Tukey HSD post hoc comparison. $1=6$-year-old, $2=9$-year-old, $3=12$-year-old, $4=15$-year-old, $5=$ adult. $*=p<0.05, * *=p<0.001$.

\section{Foraging and Executive Functions}

Due to multicollinearity of the independent measures, PLS-SEM modeling was used to explore the relationship between executive functions and foraging. The dependent measures selected for the model were the switch costs and error rates of the conjunction trials, the number of runs of the feature trials, and the mean inter-target times of each participant, collapsed over the two foraging conditions. Running the model with ITTs in feature and conjunction trials separately resulted in outer path loadings of 0.953 and 0.957 , respectively, and did not affect the inner loadings, reliability or validity of the model. We decided to collapse those two measures to simplify the model. The rest of the foraging measures were excluded because of their truncated range. Table 3 shows summary statistics of the executive function measures that were used in the model. Since both executive functions and foraging performance covary with age, a measure of age was added to the model to prevent confounding. 
Table 3. Summary statistics (mean and standard deviation) of executive functioning measures divided by age group.

\begin{tabular}{|c|c|c|c|c|c|c|c|c|}
\hline & \multicolumn{2}{|c|}{ Inhibition } & \multicolumn{2}{|c|}{$\begin{array}{l}\text { Attentional } \\
\text { flexibility }\end{array}$} & \multicolumn{2}{|c|}{ Working memory } & \multicolumn{2}{|c|}{ Problem solving } \\
\hline & M (n) & sd (n) & $\mathrm{M}(\mathrm{ms})$ & $\mathrm{sd}(\mathrm{ms})$ & $\mathrm{M}(\mathrm{ms})$ & $\mathrm{sd}(\mathrm{ms})$ & $M(n)$ & $\mathrm{sd}(\mathrm{n})$ \\
\hline 6 years & 5.44 & 3.79 & 618.61 & 273.22 & 2323.44 & 708.25 & 54.22 & 20.619 \\
\hline 9 years & 3.69 & 3.55 & 560.63 & 176.84 & 2172.50 & 657.06 & 41.19 & 16.97 \\
\hline 12 years & 3.13 & 2.36 & 335.72 & 174.92 & 1780.75 & 609.13 & 30.88 & 11.19 \\
\hline 15 years & 1.63 & 1.15 & 260.13 & 82.07 & 1884.63 & 392.28 & 18.63 & 9.63 \\
\hline Adult & 0.95 & 0.95 & 230.40 & 70.03 & 1487.55 & 399.73 & 18.65 & 16.22 \\
\hline
\end{tabular}

Note: Inhibition is measured in the mean number of false alarms. Problem solving is measured in the number of moves it took to complete the task.

Measurement model assessment. The first step in evaluating a reflective PLS-SEM model is assessing its reliability and validity. Indicator reliability is measured with their loadings onto latent variables. Hair and colleagues (2019) propose that indicator loadings lower than 0.708 are unreliable and should be removed from the model. The loadings of the number of runs, errors, and working memory were $0.595,0.621$, and 0.629 respectively. Removing only the number of runs results in adequate model reliability, so given the exploratory purposes of the model it was decided not to remove error rates and working memory. All other indicator loadings were 0.729 and higher (see Figure 4). Chronbach's alpha and composite reliability are used to assess the internal consistency reliability of the model. In exploratory models like the current one, values of 0.6 or higher are acceptable (Ali et al., 2018; Hair et al., 2019). Chronbach's alpha is considered to be conservative and underestimate the true reliability of the measures, while composite reliability is liberal and may overestimate the reliability. It can therefore be assumed that true values lie somewhere between the two coefficients (Diamantopoulos, Sarstedt, Fuchs, Wilczynski, \& Kaiser, 2012; Hair et al., 2019). Table 4 shows the internal consistency reliability of the PLS model. All values are $>0.6$ and therefore acceptable for exploratory analyses. Convergent validity is measured with the average variance extracted (AVE), if it is above 0.5, the construct explains 
over half of the variance of its items (Chin, 1998; Ringle et al., 2018). In the current model, all AVE coefficients are $>0.5$, indicating that explained variance is sufficiently high.

Table 4. Internal consistency reliability and convergent validity of the PLS-SEM model.

\begin{tabular}{lccc}
\hline & $\begin{array}{c}\text { Cronbach's } \\
\text { alpha }\end{array}$ & $\begin{array}{c}\text { Composite } \\
\text { reliability }\end{array}$ & AVE \\
\hline Age & 1.00 & 1.00 & 1.00 \\
Executive functions & 0.743 & 0.842 & 0.578 \\
Foraging & 0.635 & 0.804 & 0.587 \\
\hline
\end{tabular}

Note: AVE = average variance extracted

The heterotrait-monotrait ratio (HTMT) and cross loadings of the indicators onto the latent variables were used to assess discriminant validity. The HTMT measures the correlations between indicators from different latent variables and compares it with correlations of indicators loading onto the same latent variables (Henseler, Ringle, \& Sarstedt, 2015). If the HTMT value is below 1, discriminant validity has been affirmed. In the current model, the HTMT value of age and executive functions is 0.74 and age and foraging 0.77 . But the HTMT value of executive functions and foraging is 1.10 , which suggests that discriminant validity is not optimal. Another way of evaluating discriminant validity is by assessing crossloadings. When models have good discriminant validity, indicators load highly onto their intended latent variable and cross-loadings onto other latent variables are low. A rule of thumb is that intended loadings should be $>0.7$ and cross loadings should be $<0.4$ (Falk \& Miller, 1992; Garson, 2016). A minimum requirement is that each indicator loads higher onto its own latent variable than other latent variables (Garson, 2016). Table 5 shows the loadings of indicators onto latent variables. Cross-loadings are high, but the minimum requirement of each indicator loading highest onto the intended variable is reached. 
Table 5. Loadings of indicator variables onto latent variables.

\begin{tabular}{lccc}
\hline & Age & Executive functions & Foraging \\
\hline Age & $\mathbf{1 . 0 0}$ & -0.640 & -0.622 \\
Inhibition & -0.455 & $\mathbf{0 . 7 2 5}$ & 0.540 \\
Attentional flexibility & -0.555 & $\mathbf{0 . 8 3 1}$ & 0.627 \\
Working memory & -0.453 & $\mathbf{0 . 6 2 9}$ & 0.499 \\
Problem solving & -0.485 & $\mathbf{0 . 8 4 2}$ & 0.708 \\
ITTs & -0.581 & 0.761 & $\mathbf{0 . 8 9 4}$ \\
Switch costs & -0.392 & 0.572 & $\mathbf{0 . 7 5 3}$ \\
Errors & -0.438 & 0.411 & $\mathbf{0 . 6 2 1}$ \\
\hline
\end{tabular}

Note: Loadings onto intended latent variables are displayed in bold.

Structural model assessment. The second step of the model assessment is evaluation of the structural model, which includes measuring the path coefficients, collinearity, $\mathrm{R}^{2}$, and the predictive power of the model (Hair et al., 2019). Table 6 displays the inner model effects. The direct effects are the path loadings seen in Figure 4. The indirect effects show the effects of age on foraging through executive functions. The total effects are the sums of direct and indirect effects. All effects are significant (see Figure 4). The direct effect of age on foraging decreases significantly when the effects of executive functions are taken into account. There is a considerable indirect effect of age on foraging through executive functions which means that the age differences in Figure 3 and Table 2 reflect maturation of executive functions to a large extent. Every indicator loads strongly onto the latent executive functioning variable, indicating that they all affect foraging.

Table 6. Inner model effects.

\begin{tabular}{lccc}
\hline & Direct effects & Indirect effects & Total effects \\
\hline Age $\rightarrow$ Executive functions & -0.640 & --- & -0.640 \\
Age $\rightarrow$ Foraging & -0.201 & -0.420 & -0.622 \\
Executive functions $\rightarrow$ Foraging & 0.657 & --- & 0.657 \\
\hline
\end{tabular}




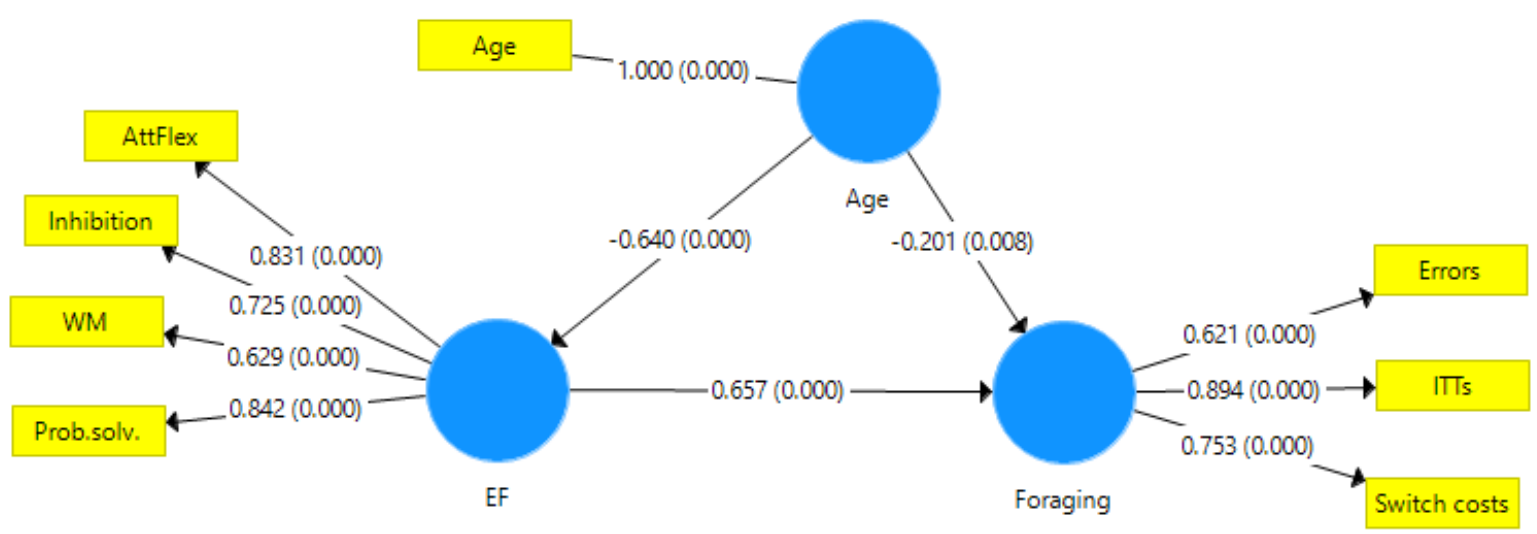

Figure 4. A PLS-SEM model of the relationship between age, executive functions (EF) and foraging. Numbers on arrows represent path loadings, $p$-values acquired by bootstrapping are shown in parentheses. AttFlex. = attentional flexibility, $\mathrm{WM}=$ working memory, Prob.solv. = problem solving, ITTs $=$ inter-target times.

The variance inflation factor (VIF) is used to assess collinearity. If the VIF coefficient is higher than 5 (Hair, Ringle, \& Sarstedt, 2011) or a stricter 3.33 (Diamantopoulos \& Siguaw, 2006) there may be a problem with collinearity. Table 7 shows that even according to the more conservative criterion, the model does not show multicollinearity between the latent variables. The explained variance for the latent variables is moderately high. The StoneGeisser $\mathrm{Q}^{2}$ and the $\mathrm{Q}^{2}$ predict coefficients are acquired with blindfolding and PLSpredict crossvalidation techniques, where values of $0.02,0.15$ and 0.35 are interpreted as weak, moderate and strong, respectively (Cohen, 1988, Garson, 2016). With $\mathrm{Q}^{2}$ and $\mathrm{Q}^{2}$ predict values between 0.23 and 0.37 , the model's predictive power is moderate to strong. 
Table 7. Structural evaluation of the PLS-SEM model.

\begin{tabular}{lcccc}
\hline & VIF & $\begin{array}{c}\mathrm{R}^{2} \\
\text { adjusted }\end{array}$ & $\mathrm{Q}^{2}$ & $\mathrm{Q}^{2}$ predict \\
\hline Age & 1.00 & --- & --- & --- \\
Executive functions & 1.694 & 0.432 & 0.225 & 0.333 \\
Foraging & 1.694 & 0.645 & 0.340 & 0.371 \\
\hline
\end{tabular}

Note: VIF = variance inflation factor.

To summarize, the PLS-SEM model is adequately reliable and valid while its discriminant validity could be higher. The main conclusions from the model are that executive functions and foraging are highly related, and that the effects of age on foraging can predominantly be attributed to the maturation of executive functions. Cross validation revealed that the predictive power of the model is moderate to strong, indicating that the same or similar results should be obtained in a new study with a different sample of participants.

\section{Discussion}

For the first time in the literature, we used a cross-sectional experimental design with foraging to investigate the development of visual attention and multiple executive functions, spanning ages from early childhood until adulthood. We have both replicated and built upon previous findings on the development of foraging abilities. In Ólafsdóttir et al. (2016) the foraging of four to seven-year-old children was measured and compared with adult performance. The findings suggested that the youngest participants had great difficulty foraging for conjunctively defined targets. Many of them were unable to complete even a single conjunction trial. They foraged more slowly than adults in both feature and conjunction foraging trials, and refrained from switching between target types, even during feature foraging. This is of great interest since it is in direct contrast with results from single target visual search studies, which have found little or no differences between feature search of young children and adults (Gerhardstein \& Rovee-Collier, 2002; Merrill \& Conners, 2013; Merrill \& Lookado, 2004). Once again this showed how foraging tasks are far more sensitive 
to the dynamics of visual attention than single-target search tasks (see Kristjánsson et al., 2019, for review). The foraging abilities of 11 to 12-year-old children, on the other hand, were similar to those of adults. The 11 to 12 -year-old children foraged as quickly, their switch costs were the same, and they completed trials in as many runs as adult participants (Ólafsdóttir et al., 2019).

In the current study, we found improvements in all measured aspects of foraging performance up until age 12, where it levels off into performance comparable to adults on three out of four measures. More specifically, ITTs and switch costs gradually decrease until age 12, where participants have reached adult levels of both foraging speed and the cost of switching, while there is a distinct fall in error rates of conjunction foraging trials between ages nine and 12. The nine year old participants make as many errors as six year olds, but forage faster, both within runs and while switching. The number of runs during feature foraging continues to increase into adulthood, although other measures stabilized after age 12, which means that increased switching between target types does not result in slowing down or more errors, and the lack of decline in switch costs as the number of runs go up indicate that it is not the cost of switching that affects decisions about switches between target types, but rather some sort of strategizing or reasoning about how to best complete the trials. These results were obtained even though the number of items on the screen was only half of what was displayed in previous studies (Ólafsdóttir et al., 2016; 2019), indicating that these age effects emerge even in relatively easy tasks.

\section{Executive Functions and Foraging}

There is some prior evidence for a connection between foraging and executive functions. Previous research with four to seven year old children, 11 to 12 year old children and adults has shown that foraging speed and switch costs (Ólafsdóttir et al., 2016; 2019), but not the number of runs (Jóhannesson et al., 2017; Ólafsdóttir et al., 2016; 2019) are connected 
with attentional flexibility and working memory. A study on patch leaving behavior during foraging for information showed that older adults with greater executive control were able to adjust their patch leaving decisions to maximize information gain, while seniors with lower executive control abilities tended to persist in the same patch even though little information was left to gain from it (Chin, Payne, Fu, Morrow, Stine-Morrow, 2015). Additionally, an archaeological study has claimed that the reason humans started to forage for food was enhanced working memory capacity (Wynn \& Coolidge, 2017).

Here, we continued this inquiry into whether, and then how, executive functions influence foraging. We added a measure of problem solving and used a simple response inhibition measure. Previous studies from our lab (Jóhannesson et al., 2017; Ólafsdóttir et al., 2019) had used a complex inhibition task, where observers had to remember an arbitrary rule, inhibit a prepotent response, and produce an alternative response. These types of inhibition tasks are taxing for working memory and the task therefore confounds these two executive functions (Best \& Miller, 2010; Garon, Bryson, \& Smith, 2008). In the Go/no-go task used in the current study, there is a simple rule to remember, but no alternative response required, only inhibition. This task should therefore be a purer measure of inhibition than the previously used tasks.

Due to multicollinearity of the executive functioning measures and a relatively small sample, PLS-SEM modeling was conducted to get an insight into the relationship between executive functions and foraging. The model's reliability and convergent validity were good, but the HTMT ratio between executive functions and foraging was too high. That means that the discriminant validity of the model might not be adequate, which indicates that executive functioning and foraging tasks measure the same abilities. The path loadings of executive functions onto foraging are indeed high, which suggest that the two constructs are highly related. Given the strong connection between executive functions and foraging found in the 
current study, it is even possible that foraging tasks could be used as a proxy for executive functional abilities. Since this study is intended to be an exploratory analysis, and the minimum requirement that no indicator cross-loading are higher than the loading onto the intended latent variable (Garson, 2016), we carried on with the analysis, but all interpretations carry this caveat.

There is a large body of research that demonstrates the importance of various conceptions of attention for children's healthy functioning, including academic performance (see e.g. Polderman, Boomsma, Bartels, Verhulst, \& Huizink, 2010; Rhoades, Warren, Domitrovich, \& Greenberg, 2011; Steinmayr, Ziegler, \& Träuble, 2010). As such, understanding how different aspects of attention develop, and how they relate to other (even overlapping) constructs, such as executive functions, helps us better understand how and when children attain this important ability. In addition, studying how executive functions relate to foraging gives us insights into our cognitive functions as we orient our attention through the environment.

The PLS-SEM model of the effect of age and executive functions on foraging can be seen in Figure 4. When the effects of executive functions are taken into account, the direct effect of age on foraging diminishes significantly. There is still a considerable indirect effect of age on foraging through executive functions, but this means that the age differences in seen in Figure 3 and Table 2 are due in large part to maturation of executive functions. All indicators load relatively highly onto the latent executive functioning variable, so they all seem to affect foraging to some degree. Interestingly, the loading of inhibition onto the latent variable is high, which suggests that inhibition is related to foraging. This relationship has not been found in previous studies, but as previously mentioned, a complex inhibition task has been used up until now, where a simple Go/no-go task was administered as an inhibition measure. 
Although the current model shows that there is a strong connection between executive functions and foraging, and that this connection accounts for age differences in foraging abilities, it does not reveal how the executive functions of each age group relate to foraging. There is some evidence that this relationship changes throughout development. Ólafsdóttir et al. (2019) found that the relationship between executive functions and foraging differed between age groups, even though there were no age differences in foraging performance. Multiple linear regression revealed that inter-target times were related to attentional flexibility in children but working memory in adults, and switch costs were related to the attentional flexibility and working memory of children, but no connection was found between switch costs and executive functions in adults.

Different executive functioning components develop at different rates (Klenberg et al., 2001; Lee et al., 2013), which can affect how executive functions relate to other constructs. Senn, Espy, and Kaufmann (2004) measured inhibition, attentional flexibility, working memory, and problem solving in children aged two to six. They found that for children younger than four years old, inhibition predicted performance on the Tower of London task, but in children between four and six years old, performance was now predicted by working memory capacity. The correlation between inhibition and working memory was also moderate in the younger age group but had disappeared in the older children. The same principle might explain the differential connections between foraging and executive functioning performance found in Ólafsdóttir et al. (2019). It is therefore an important next step to tease apart the effects of the different subcomponents of executive functions on visual attention tasks throughout development.

\section{Conclusions and Future Directions}

The foraging performance of children between ages six and twelve improves on all measures included in this study and at twelve years old, children have reached adult levels of 
performance. Foraging abilities have a strong connection with executive functions, there is a small direct effect of age on foraging, but a considerable indirect effect through executive functions. Since different components of executive functions develop at a different rate, and their relationship with each other and other constructs changes throughout development, the next step in discovering how executive functions affect foraging abilities should be to analyze this relationship separately for different age groups. Furthermore, a longitudinal study on this topic would help with confirming how these capabilities and the connection between them develop over time. 


\section{References}

Adler, S. A., \& Orprecio, J. (2006). The eyes have it: Visual pop-out in infants and adults. Developmental Science, 9(2), 189-206.

Ali, F., Rasoolimanesh, S. M., Sarstedt, M., Ringle, C. M., \& Ryu, K. (2018). An assessment of the use of partial least squares structural equation modeling (PLS-SEM) in hospitality research. International Journal of Contemporary Hospitality Management, 30(1), 514-538.

Anderson, P. (2002). Assessment and development of executive function (EF) during childhood. Child Neuropsychology, 8, 71-82.

Awh, E., \& Jonides, J. (2001). Overlapping mechanisms of attention and spatial working memory. Trends in Cognitive Sciences, 5(3), 119-126.

Ásgeirsson, Á. G., \& Kristjánsson, Á. (2019). Attentional priming does not enable observers to ignore salient distractors. Visual Cognition, 1-14.

Best, J. R. \& Miller, P. H. (2010). A developmental perspective on executive function. Child Development, 81(6), 1641-1660.

Best, J. R., Miller, P. H., \& Jones, L. L. (2009). Executive functions after age 5: Changes and correlates. Developmental Review, 29, 180-200.

Brascamp, J. W., Blake, R., \& Kristjánsson, Á. (2011). Deciding where to attend: Priming of pop-out drives target selection. Journal of Experimental Psychology: Human Perception and Performance, 37(6), 1700-1707. doi: 10.1037/ a0025636.

Bravo, M. J., \& Nakayama, K. (1992). The role of attention in different visual-search tasks. Attention, Perception, \& Psychophysics, 51(5), 465-472.

Brocki, K. C., \& Bohlin, G. (2004). Executive functions in children aged 6 to 13: A dimensional and developmental study. Developmental Neuropsychology, 26(2), 571593. 
Brunnekreef, A. J., de Sonneville, L. M., Althaus, M., Minderaa, R. B., Oldehinkel, A. J., Verhulst, F. C., \& Ormel, J. (2007). Information processing profiles of internalizing and externalizing behavior problems: Evidence from a population-based sample of preadolescents. Journal of Child Psychology and Psychiatry, 48(2), 185-193.

Bukovinszky, T., Rikken, I., Evers, S. (2017). Effects of pollen species composition on the foraging behaviour and offspring performance of the mason bee Osmia bicornis (L.). Basic and Applied Ecology, 18, 21-30.

Bundesen, C. (1990). A theory of visual attention. Psychological Review, 97(4), 523-547.

Chetverikov, A., \& Kristjánsson, Á. (2015). History effects in visual search as reflected in reaction times, choice biases, and liking. Attention, Perception \& Psychophysics, 77(2), 402-412.

Chin, W. W. (1998). The partial least squares approach to structural equation modeling. In G. A. Marcoulides (Ed.), Modern Methods for Business Research (pp. 295-336). Mahwah, NJ: Lawrence Erlbaum Associates.

Chin, J., Payne, B. R., Fu, W. T., Morrow, D. G., \& Stine-Morrow, E. A. (2015). Information foraging across the life span: Search and switch in unknown patches. Topics in Cognitive Science, 7(3), 428-450.

Cohen, J. (1988). Statistical Power Analysis for the Behavioral Sciences. Mahwah, NJ: Lawrence Erlbaum Associates.

Culbertson, W. C. \& Zillmer, E. A. (2005). Tower of London Drexel University: $2^{\text {nd }}$ Edition $\left(T O L^{D X}\right)$. Canada: Multi-Health Systems Inc.

Davidson, M. C., Amso, D., Anderson, L. C., \& Diamond, A. (2006). Development of cognitive control and executive functions from 4 to 13 years: Evidence from manipulations of memory, inhibition, and task switching. Neuropsychologia, 44(11), 2037-2078. 
Dawkins, M. (1971). Perceptual changes in chicks: another look at the 'search image' concept. Animal Behaviour, 19(3), 566-574.

De Sonneville, L. M. J. (1999). Amsterdam neuropsychological tasks: A computer-aided assessment program. In: Den Brinker BPLM, Beek PJ, Brand AN, Maarse SJ, Mulder LJM, editors. Cognitive Ergonomics, Clinical Assessment and Computer-assisted Learning: Computers in Psychology, vol. 6. Lisse: Swets, p. 187-203.

De Sonneville, L. M. J. (2011). ANT Manual. Sonares BV: Netherlands.

Diamantopoulos, A., Sarstedt, M., Fuchs, C., Wilczynski, P., \& Kaiser, S. (2012). Guidelines for choosing between multi-item and single-item scales for construct measurement: a predictive validity perspective. Journal of the Academy of Marketing Science, 40(3), 434-449.

Diamantopoulos, A., \& Siguaw, J. A. (2006). Formative versus reflective indicators in organizational measure development: A comparison and empirical illustration. British Journal of Management, 17(4), 263-282.

Diamond, A. (2002). Normal development of prefrontal cortex from birth to young adulthood: Cognitive functions, anatomy, and biochemistry. In D. Stuss and R. Knight (Eds.), Principles of Frontal Lobe Function (466-503), New York, NY: Oxford University Press.

Donnelly, N., Cave, K., Greenway, R., Hadwin, J. A., Stevenson, J., \& Sonuga-Barke, E. (2007). Visual search in children and adults: Top-down and bottom-up mechanisms. The Quarterly Journal of Experimental Psychology, 60(1), 120-136.

Falk, R. F. \& Miller, N. B. A Primer of Soft Modeling, The University of Akron Press, Akron, OH, 1992.

Garon, N., Bryson, S. E., \& Smith, I. M. (2008). Executive function in preschoolers: a review using an integrative framework. Psychological Bulletin, 134(1), 31. 
Garson, G. D. (2016). Partial least squares: Regression and structural equation models. Asheboro, NC: Statistical Associates Publishers.

Gathercole, S. E., Pickering, S. J., Ambridge, B., \& Wearing, H. (2004). The structure of working memory from 4 to 15 years of age. Developmental Psychology, 40(2), 177190.

Geisser, S. (1974). A predictive approach to the random effects model. Biometrika, 61(1), 101-107.

Geladi, P., \& Kowalski, B. R. (1986). Partial least-squares regression: a tutorial. Analytica Chimica Acta, 185, 1-17.

Gerhardstein, P., \& Rovee-Collier, C. (2002). The development of visual search in infants and very young children. Journal of Experimental Child Psychology, 81(2), 194-215.

Gil-Gómez de Liaño, B. G. G., Quirós-Godoy, M., Pérez-Hernández, E., Cain, M., \& Wolfe, J. (2018). Understanding Visual Search and Foraging in Cognitive Development. Journal of Vision, 18(10), 635-635.

Hair, J. F., Ringle, C. M., \& Sarstedt, M. (2011). PLS-SEM: Indeed a silver bullet. Journal of Marketing Theory and Practice, 19(2), 139-152.

Hair, J. F., Risher, J. J., Sarstedt, M., \& Ringle, C. M. (2019). When to use and how to report the results of PLS-SEM. European Business Review, 31(1), 2-24.

Henseler, J., Ringle, C. M., \& Sarstedt, M. (2015). A new criterion for assessing discriminant validity in variance-based structural equation modeling. Journal of the academy of marketing science, 43(1), 115-135.

Henseler, J., Ringle, C. M., \& Sinkovics, R. R. (2009). The use of partial least squares path modeling in international marketing. In New Challenges to International Marketing (pp. 277-319). Emerald Group Publishing Limited. 
Hommel, B., Li, K. Z., \& Li, S. C. (2004). Visual search across the life span. Developmental Psychology, 40(4), 545.

Huizinga, M., Dolan, C. V., \& van der Molen, M. W. (2006). Age-related change in executive function: Developmental trends and a latent variable analysis. Neuropsychologia, 44, 2017-2036.

Isquith, P. K., Gioia, G. A., \& Espy, K. A. (2004). Executive function in preschool children: Examination through everyday behavior. Developmental Neuropsychology, 26(1), 403-422.

Jenkins, I. L., \& Berthier, N. E. (2014). Working memory and inhibitory control in visually guided manual search in toddlers. Developmental Psychobiology, 56(6), 1252-1262.

Johnstone, S. J., Dimoska, A., Smith, J. L., Barry, R. J., Pleffer, C. B., Chiswick, D., \& Clarke, A. R. (2007). The development of stop-signal and Go/Nogo response inhibition in children aged 7-12 years: Performance and event-related potential indices. International Journal of Psychophysiology, 63, 25-38.

Jóhannesson, Ó. I., Kristjánsson, Á., \& Thornton, I. M. (2017). Are foraging patterns in humans related to working memory and inhibitory control? Japanese Psychological Research, 59(2), 152-166.

Jöreskog, K. G. (1973). A general method for estimating a linear structural equation system. In A. S. Goldberger \& O. D. Duncan (Eds.), Structural Equation Models in the Social Sciences (pp. 85-112). New York: Academic Press.

Klenberg, L., Korkman, M., \& Lahti-Nuuttila, P. (2001). Differential development of attention and executive functions in 3-to-12-year-old Finnish children. Developmental Neuropsychology, 20(1), 407-428.

Kristjánsson, Á. (2015). Reconsidering Visual Search. i-Perception, 6(6), 2041669515614670. 
Kristjánsson, Á., \& Egeth, H. (2020). How feature integration theory integrated cognitive psychology, neurophysiology, and psychophysics. Attention, Perception, \& Psychophysics, 82, 7-23.

Kristjánsson, Á., Jóhannesson, Ó. I., \& Thornton, I. M. (2014). Common attentional constraints in visual foraging. PloS One, 9(6), e100752.

Kristjánsson, Á., Ólafsdóttir, I. M., \& Kristjánsson, T. (2019). Visual Foraging Tasks Provide New Insights into the Orienting of Visual Attention: Methodological Considerations. In: Neuromethods. Humana Press.

Kristjánsson, T., Thornton, I. M., \& Kristjánsson, Á. (2018). Time limits during visual foraging reveal flexible working memory templates. Journal of Experimental Psychology: Human Perception and Performance, 44(6), 827.

Kristjánsson, T., Thornton, I. M., Chetverikov, A., \& Kristjánsson, Á. (2020). Dynamics of visual attention revealed in foraging tasks. Cognition, 194, 104032.

Lee, K., Bull, R., \& Ho, R. M. H. (2013). Developmental changes in executive functioning. Child Development, 84(6), 1933-1953.

Leon-Carrion, J., Garcia-Orza, J., \& Perez-Santamaria, F. J. (2004). Development of the inhibitory component of the executive functions in children and adolescents. International Journal of Neuroscience, 114, 1291-1311.

Longstaffe, K. A., Hood, B. M., \& Gilchrist, I. D. (2014). The influence of cognitive load on spatial search performance. Attention, Perception, \& Psychophysics, 76(1), 49-63. Maljkovic, V., \& Nakayama, K. (1994). Priming of pop-out: I. Role of features. Memory \& cognition, 22(6), 657-672.

Mallott, E. K., Garber, P. A., \& Malhi, R. S. (2017). Integrating feeding behavior, ecological data, and DNA barcoding to identify developmental differences in invertebrate 
foraging strategies in wild white-faced capuchins (Cebus capucinus). American Journal of Physical Anthropology, 162(2), 241-254.

Merrill, E. C., \& Conners, F. A. (2013). Age-related interference from irrelevant distracters in visual feature search among heterogeneous distracters. Journal of Experimental Child Psychology, 115(4), 640-654.

Merrill, E. C., \& Lookadoo, R. (2004). Selective search for conjunctively defined targets by children and young adults. Journal of Experimental Child Psychology, 89(1), 72-90.

Mesotten, D., Gielen, M., Sterken, C., Claessens, K., Hermans, G., Vlasselaers, D., ... \& Vanhorebeek, I. (2012). Neurocognitive development of children 4 years after critical illness and treatment with tight glucose control: a randomized controlled trial. Jama, $308(16), 1641-1650$.

Miyake, A., Friedman, N. P., Emerson, M. J., Witzki, A. H., Howerter, A., \& Wager, T. D. (2000). The unity and diversity of executive functions and their contributions to complex "frontal lobe" tasks: A latent variable analysis. Cognitive Psychology, 41, 49100.

Ólafsdóttir, I. M., Gestsdóttir, S. \& Kristjánsson, Á. (2019). Visual foraging and executive functions: A developmental perspective. Acta Psychologica, 193, 203-213.

Ólafsdóttir, I. M., Kristjánsson, T., Gestsdóttir, S., Jóhannesson, Ó. I., \& Kristjánsson, Á. (2016). Understanding visual attention in childhood: Insights from a newly developed foraging task. Cognitive Research: Principles and Implications 1(1), 18-29. DOI 10.1186/s41235-016-0016-5.

Polderman, T. J. C., Boomsma, D. I., Bartels, M., Verhulst, F. C., \& Huizink, A. C. (2010). A systematic review of prospective studies on attention problems and academic achievement. Acta Psychiatrica Scandinavica, 122(4), 271-284. 
Pureza, J. R., Gonçalves, H. A., Branco, L., Grassi-Oliveira, R., \& Fonseca, R. P. (2013). Executive functions in late childhood: age differences among groups. Psychology \& Neuroscience, 6(1), 79-88.

Pyke, G. H., Pulliam, H. R., \& Charnov, E. L. (1977). Optimal foraging: A selective review of theory and tests. The Quarterly Review of Biology, 52(2), 137-154.

Quirós-Godoy, M., Pérez-Hernández, E., Cain, M., Wolfe, J., \& Gil-Gómez de Liaño, B. (2018). Individual Differences in Visual Search and Foraging in children. Journal of Vision, 18(10), 637.

Rhoades, B. L., Warren, H. K., Domitrovich, C. E., \& Greenberg, M. T. (2011). Examining the link between preschool social-emotional competence and first grade academic achievement: The role of attention skills. Early childhood research quarterly, 26(2), 182-191.

Ringle, C. M., Sarstedt, M., Mitchell, R., \& Gudergan, S. P. (2018). Partial least squares structural equation modeling in HRM research. The International Journal of Human Research Management, DOI: 10.1080/09585192.2017.1416655.

Sarstedt, M., Ringle, C. M., Smith, D., Reams, R., \& Hair Jr, J. F. (2014). Partial least squares structural equation modeling (PLS-SEM): A useful tool for family business researchers. Journal of Family Business Strategy, 5(1), 105-115.

Senn, T. E., Espy, K. A., \& Kaufmann, P. M. (2004). Using path analysis to understand executive function organization in preschool children. Developmental Neuropsychology, 26(1), 445-464.

Schuitema, I., Deprez, S., Van Hecke, W., Daams, M., Uyttebroeck, A., Sunaert, S., ... \& Veerman, A. J. (2013). Accelerated aging, decreased white matter integrity, and associated neuropsychological dysfunction 25 years after pediatric lymphoid malignancies. Journal of Clinical Oncology, 31(27), 3378-3388. 
Shmueli, G., Sarstedt, M., Hair, J. F., Cheah, J. H., Ting, H., Vaithilingam, S., \& Ringle, C. M. (2019). Predictive model assessment in PLS-SEM: guidelines for using PLSpredict. European Journal of Marketing, 53(11), 2322-2347.

Steinmayr, R., Ziegler, M., \& Träuble, B. (2010). Do intelligence and sustained attention interact in predicting academic achievement? Learning and Individual Differences, 20(1), 14-18.

Stone, M. (1974). Cross-validatory choice and assessment of statistical predictions. Journal of the Royal Statistical Society, 36(2), 111-147.

Taylor, M. J., Chevalier, H., \& Lobaugh, N. J. (2003). Discrimination of single features and conjunctions by children. International Journal of Psychophysiology, 51(1), 85-95.

Treisman, A. M., \& Gelade, G. (1980). A feature-integration theory of attention. Cognitive Psychology, 12(1), 97-136.

Trick, L. M., \& Enns, J. T. (1998). Lifespan changes in attention: The visual search task. Cognitive Development, 13(3), 369-386.

Werner, H. (1957). The concept of development from a comparative and organismic point of view. In D. Harris (Ed.), The Concept of Development. Minneapolis, MN: University of Minnesota Press.

Wiebe, S. A., Sheffield, T., Nelson, J. M., Clark, C. A., Chevalier, N., \& Espy, K. A. (2011). The structure of executive function in 3-year-olds. Journal of Experimental Child Psychology, 108(3), 436-452.

Willoughby, M. T., Blair, C. B., Wirth, R. J., \& Greenberg, M. (2010). The measurement of executive function at age 3 years: psychometric properties and criterion validity of a new battery of tasks. Psychological Assessment, 22(2), 306. 
Willoughby, M. T., Wirth, R. J., \& Blair, C. B. (2012). Executive function in early childhood: Longitudinal measurement invariance and developmental change. Psychological Assessment, 24(2), 418.

Wolfe, J. M. (1994). Guided Search 2.0: A revised model of visual search. Psychonomic Bulletin \& Review, 1(2), 202-238.

Wolfe, J. M. (2013). When is it time to move to the next raspberry bush? Foraging rules in human visual search. Journal of Vision, 13(3), 1-17.

Wolfe, J. M., \& Horowitz, T. S. (2017). Five factors that guide attention in visual search. Nature Human Behaviour, 1(3), 0058.

Woods, A. J., Göksun, T., Chatterjee, A., Zelonis, S., Mehta, A., \& Smith, S. E. (2013). The development of organized visual search. Acta Psychologica, 143(2), 191-199.

Wu, K. K., Chan, S. K., Leung, P. W., Liu, W. S., Leung, F. L., \& Ng, R. (2011). Components and developmental differences of executive functioning for school-aged children. Developmental Neuropsychology, 36(3), 319-337.

Wynn, T. G., \& Coolidge, F. L. (Eds.). (2017). Cognitive Models in Palaeolithic Archaeology. Oxford University Press.

Zelazo, P. D. (2015). Executive function: Reflection, iterative reprocessing, complexity, and the developing brain. Developmental Review, 38, 55-68.

Zelazo, P. D., Blair, C. B., \& Willoughby, M. T. (2016). Executive Function: Implications for Education. NCER 2017-2000. National Center for Education Research. 